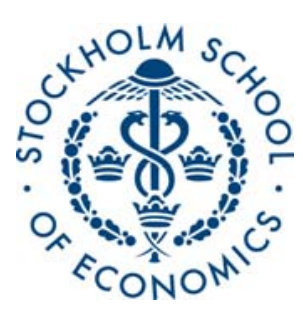

\title{
CHINA'S FINANCIAL MARKET INTEGRATION WITH THE WORLD
}

Anders C. Johansson

Stockholm School of Economics

\section{CERC Working Paper 10}

June 2009

Postal address: P.O. Box 6501, S-113 83 Stockholm, Sweden.

Office address: Holländargatan 30 Telephone: +46 87369360 Telefax: +46 8313017

E-mail: japan@hhs.se Internet: http://www.hhs.se/cerc 


\title{
China's Financial Market Integration with the World
}

\author{
Anders C. Johansson* \\ Stockholm School of Economics
}

This version: May 2009

\begin{abstract}
It is commonly argued that China's financial markets are effectively insulated from the rest of the world. To see if this is true and to better understand China's financial development, we analyze China's integration with major financial markets. Using conditional copulas, we show that China has experienced an increasing level of integration with several major financial markets during the last decade, even though the country's financial markets are commonly seen as being insulated. Furthermore, the level of integration has increased with several major markets during the current financial crisis. The results and possible reasons for the increasing integration are analyzed and the implications for policymakers and market participants are discussed.
\end{abstract}

Keywords: China; Financial market integration; Codependence; Copula

JEL Classification: F30; G15

*E-mail: anders.johansson@hhs.se. Stockholm School of Economics, P.O. Box 6501, 113 83 Stockholm, Sweden. Financial support from the Bank of Sweden Tercentenary Foundation, the Swedish Foundation for International Cooperation in Research and Higher Education, and the Swedish School of Advanced Asia-Pacific Studies (SSAAPS) is gratefully acknowledged. 


\section{Introduction}

Financial integration has been increasing around the world during the last decades. ${ }^{1}$ Reasons for this include the tendency for investors turning to other markets for diversification and higher returns as well as financial liberalization in a large number of both developed and developing economies. Private capital flows across national borders have increased fast and developing countries with their expected high levels of economic growth have been recipients of a significant amount of these flows. There are significant potential benefits to be had as a result of increasing financial integration for both developed and developing countries. The possibility of diversification of savings should have a direct positive effect on individuals' wealth. Consumption smoothing is another potential benefit (see Obstfeld, 1994, among others). However, many regional financial crises and episodes of so-called financial contagion show that more open access to international financial markets also brings with it potential risks for individuals and the economy as a whole. Even though most financial crises are the direct result of misaligned fundamentals (Agénor, 2003), these crises have shown the importance of having developed strong domestic financial systems with efficient regulatory overview and supervision. In the case of China, the government is taking financial liberalization step by step. For instance, instead of opening up for cross-border investments immediately, the country has created programs for qualified domestic investors that are allowed to invest abroad, as well as qualified foreign investors allowed to invest in the domestic financial markets. Another example of controlled cross-border transactions is the fact that the Chinese market has been divided into shares of different classes, where A-shares are for domestic investors, while B-shares are for foreign (and now also domestic) market participants. Overall, it seems clear that the Chinese government sees the potential benefits of a higher level of financial integration with the rest of the world. The high domestic savings rates and the reforms of the domestic pension system also create a strong demand for alternative investments besides those available in the domestic financial markets.

The aim of this paper is to analyze China's financial integration with neighboring countries as well as other regions around the world. To better understand how such integration changes over time, we focus on financial market integration, and more specifically integration between the Chinese equity market and other equity markets. One of the novelties in this paper is the focus on China's financial integration with nearby markets as well as regions. Another, and perhaps more important novelty is the new approach we use to study dependence between different markets. To analyze China's financial market integration with the rest of the world, we use both unconditional and conditional

\footnotetext{
${ }^{1}$ For an interesting discussion on financial globalization over the past two decades, see Moshirian (2008). Also, for a discussion on regional economic and financial integration in Asia and China's role in that process, see Moshirian (2009).
} 
copulas. Copulas have recently become popular in the finance literature due to a number of reasons. It can be argued that copulas are more informative measures of dependence between variables than standard linear correlation. This is the case when the joint distribution of the variables is nonelliptical and the typical linear correlation measure is not enough to describe the dependence between the variables (Patton, 2006). Copulas have been used to study the asymmetric nature of dependence between financial variables (e.g. Patton, 2006) as well as contagion (Rodriguez, 2007). The empirical results in this paper indicate that China is moving from a very low level of financial market integration. The last two decades show signs of how China's financial markets are becoming increasingly dependent on markets in the rest of the world. A number of reasons for why this development is taking place are discussed, including the gradual opening up of the domestic markets to the outside world, cross-listings, the internationalization of Chinese firms, and the general economic integration around the world.

The rest of the paper is organized as follows: Section 2 discusses related literature on financial integration and the Chinese financial markets. Section 3 introduces the methodology of copulas and how it is used to study the dependence structure among financial variables. Section 4 goes over the empirical results. Section 5 discusses possible reasons for China's changing financial market integration with the rest of the world, and Section 6 concludes the paper.

\section{Literature Review}

The literature on market integration is rich and includes both theoretical and empirical studies. Important studies include Solnik (1974), Stehle (1977), Stulz (1981), Jorion and Schwartz (1986), Eun and Janakiramanan (1986), Harvey (1991), Sellin and Werner (1993), Bailey and Jagtiani (1994), Stulz and Wasserfallen (1995), and Carrieri, Errunza, and Hogan (2007). How can we define financial market integration? Following Bekaert and Harvey (1995), markets can be said to be fully integrated if assets with identical risk have identical expected returns regardless of in which market they are traded. Early research looked at how financial integration is taking place over time and across borders in both developed and developing parts of the world. Bekaert and Harvey's (1995) study on a large number of developed countries and twelve emerging markets showed that some emerging markets seem to be more integrated with other markets even though there are strong investment restrictions in place. On the other hand, their study indicates that other emerging markets are segmented, even though foreign investors have relatively free access to investment opportunities. Their results thus indicate the possibility of increasing financial market integration over time even when a market appears to be quite insulated from the rest of the world's markets. Their findings are interesting and of significant important to this study, since we focus on a market that is com- 
monly seen as being very much insulated from the rest of the world. There are also a number of studies that look at the gradual nature of market integration. Bekaert (1995) analyzes regulatory changes and market integration. His results indicate that set dates with regulatory changes do not significantly relate to market integration, indicating that integration is gradual in nature. Similarly, Bekaert, Harvey, and Lumsdaine (2002) identify endogenous break dates in the level of market integration and show that these dates do not necessarily correspond well with dates of official market reforms.

In terms of financial integration in general, a common argument in research on financial integration in East Asia is that most of the integration taking place is not so much on a regional level, but rather on a global level. For instance, Eichengreen and Park (2005) show that East Asian countries have stronger financial ties with Western Europe and the U.S. than neighboring countries in the region. Joen, Oh and Yang (2005), looking at financial market data, find support for this argument. As a latecomer on the stage of regional financial markets, China constitutes an interesting case. This paper therefore looks at how the Chinese stock market relates not only to important markets close by, such as Hong Kong and Japan, but also to the rest of Asia, Europe, and the U.S.

There is a growing number of studies that focus on China's financial relationship with neighboring economies. Shin and Sohn (2006) analyze trade and financial integration in Asia and include China in their sample. To identify possible regional financial integration, they focus on co-movements in interest rates using standard correlation measures. They find that the current level of financial integration in the region is low and that it is difficult to identify the possible effects that financial integration has on macroeconomic variables such as output and consumption. In a study on spillover effects among financial markets, Johansson and Ljungwall (2009) focus on the equity markets in the so-called Greater China region (China, Taiwan, and Hong Kong). They show that there are spillover effects between the markets and that the Chinese market is affected by its neighbors even though it is commonly seen as an insulated market. Cheung, Chinn and Fujii (2003) study financial integration in the Greater China region. Using data on interbank rates, exchange rates, and prices, they show that there is an increasing trend in financial integration in the region, especially between China and Hong Kong. In a related study, Cheung, Chinn and Fujii (2005) analyze financial integration in Greater China and how its economies are integrated with the rest of the world. Their findings indicate that the money markets in the Greater China region are increasingly linked to the world's money markets, but that the banking sector on the mainland remains insulated from banking sectors in other countries. Finally, Wang and Di Iorio (2007) show that there is an increasing integration between China's A-share market and Hong Kong's stock market, but that there is no evidence that the Chinese A-share market is becoming more integrated with the world market. 
A number of reasons for why Asia's financial integration is lagging behind that of regions such as Europe have been discussed in the literature on regional financial integration. When it comes to China, Masson, Dobson and Lafrance (2008) argue that China is less financially integrated with the rest of the world, even though the country is becoming more and more important for the world economy. The authors list a number of reasons for why this may change over the coming decades, including China's increasing investments abroad, the continued development of the domestic financial system, a development towards a more flexible exchange rate system, and the possibility of a continuation of the relaxation of capital controls. These reasons for anticipating China's increasing level of financial integration with the rest of the world are important, as is a more detailed analysis of why financial integration is already increasing as seen in this study. This is why a separate section in this paper focuses on possible reasons for why China's financial integration with the rest of the world is increasing and why this trend is likely to continue.

\section{Methodology}

In this section, we introduce the concept of copulas and extend it to a conditional specification of co-dependence. The discussion is kept brief and most of the content is based on Nelson (1999) and Patton (2006). The theory of copulas allows us to decompose a joint distribution of two or more variables into their marginal distributions and the dependence function, i.e. the copula. In this study, we use bivariate copulas and will therefore focus the following discussion on a bivariate setting. It should be noted that the theory is easily extended to a multivariate setting. Following the original work on copulas by Sklar (1959) and the explanation by Patton (2006), we can decompose the joint distribution into the marginal distributions:

$$
F_{X Y}(x, y)=C\left(F_{X}(x), F_{Y}(y)\right),
$$

where $F_{X Y}$ is the cumulative distribution function and $F_{X}(x)$ and $F_{Y}(y)$ are the marginal distributions, respectively. If we instead use density functions, the relationship can be written as:

$$
f_{x y}(x, y)=f_{x}(x) \cdot f_{y}(y) \cdot c\left(F_{x}(x) F_{y}(y)\right) .
$$

If the distribution function $F_{X Y}(x, y)$ is a continuous multivariate distribution function, Sklar's theorem shows that we can separate the marginal distribution for the two variables from that of the dependence structure. There are several reasons for why copulas in many situations are preferable to other measures of dependence (see, for example, Rodriguez, 2007, for an excellent discussion on the statistical properties of copulas). Here, it suffices to say that copulas are advantageous compared to another commonly used measure of dependence, namely correlation. While correlation only captures the linear relationship between two variables, copulas contain all the information about the dependence 
between them. As Rodriguez (2007) points out, copulas are especially useful when it comes to analyzing the information about the tails of the joint distribution of the variables in question. Carrieri, Errunza, and Hogan (2007) show that correlation is not an appropriate measure of financial market integration because it underestimates the degree of integration. Since copulas measures the full dependence between variables, we believe that our approach is better suited to look at financial market integration.

Patton (2006) developed the concept of copulas to allow for a time-varying behavior of the dependence structure between variables. This concept is perhaps especially useful when analyzing economic and financial variables, as it allows us to understand how the dependence structure evolves over time. Let us assume that there is a conditioning variable, $W$, and that its dimension is 1. Patton (2006) defines a conditional copula of $(X, Y) \mid W=w$, where $X \mid W=w \sim F_{X \mid W}(\cdot \mid w)$ and $Y \mid W=w \sim F_{Y \mid W}(\cdot \mid w)$ is the conditional joint distribution function of $U \equiv F_{X \mid W}(X \mid w)$ and $V \equiv F_{Y \mid W}(Y \mid w)$, given $W=w$. Here, the variables $U$ and $V$ are the so-called probability integral transforms of $X$ and $Y$ given $W$. The probability integral transforms $U$ and $V$ have a Unif $(0,1)$ distribution (Fisher, 1932, and Rosenblatt, 1952). According to Patton (2006), conditional copulas have the same properties as unconditional copulas. He also shows how to extend Sklar's original theorem to the conditional case.

There are many ways to parameterize conditional copulas (for different approaches, see Patton, 2006, and Rodriguez, 2006). Here, we follow the approach in Patton (2006). Focusing on the conditional normal (Gaussian) copula and considering the bivariate setting, we can write the dependence function as:

$$
C(u, v \mid \rho)=\int_{-\infty}^{\Phi^{-1}(u)} \int_{-\infty}^{\Phi^{-1}(v)} \frac{1}{2 \pi \sqrt{\left(1-\rho^{2}\right)}} \exp \left\{\frac{-\left(r^{2}-2 \rho r s+s^{2}\right)}{2\left(1-\rho^{2}\right)}\right\} d r d s
$$

where $-1<\rho<1$. In equation (3), $\Phi^{-1}$ is the inverse of the standard normal cumulative distribution function. Patton (2006) suggests the following evolution equation for $\rho_{t}$ :

$$
\rho_{t}=\tilde{\Lambda}\left(\omega_{\rho}+\beta_{\rho} \rho_{t-1}+\alpha \frac{1}{10} \sum_{j=1}^{10} \Phi^{-1}\left(u_{t-j}\right) \Phi^{-1}\left(v_{t-j}\right)\right) .
$$

To keep $\rho_{t}$ in $(-1,1)$ at all times, $\tilde{\Lambda}$ is the modified logistic transformation, defined as:

$$
\tilde{\Lambda} \equiv \frac{1-e^{-x}}{1+e^{-x}}=\tanh \left(\frac{x}{2}\right) .
$$

The second part in the parenthesis on the right-hand side of equation (4) is included to allow for persistence in the dependence parameter. The third part is meant to capture the variation in the parameter and is composed of the 
mean of the product of the last 10 observations of the inverse of the cumulative distribution functions of $u$ and $v$.

In practice, there are three basic steps involved when one wants to obtain the dependence structure between two variables. First, the two marginal distributions are modeled using a suitable specification. Then, a probability integral transform is used to convert the standardized residuals of the marginal distributions into $\operatorname{Unif}(0,1)$ distributions. Finally, the uniform distributions are used to obtain the dependence structure between the two variables. ${ }^{2}$. Since we are focusing on the dependence structure between pairs of equity markets, a natural choice for the marginal distributions are models that take heteroscedastic features of most financial markets into account. We choose to model the conditional volatility in the different markets using three possible GARCH specifications: the standard GARCH developed by Bollerslev (1986); the threshold, or TGARCH model, developed by Glosten, Jaganathan, and Runkle (1993); and the exponential, or EGARCH, model developed by Nelson (1991). We apply all three specifications to all markets and choose the most suitable specification for each market based on Akaike's information criterion. The three specifications can be described as follows:

\section{GARCH}

$$
\sigma_{t}^{2}=\omega+\sum_{j=1}^{q} \beta_{j} \sigma_{t-j}^{2}+\sum_{i=1}^{p} \alpha_{i} \epsilon_{t-i}^{2}
$$

Here, $\sigma_{t}^{2}$ is the conditional variance, $\sigma_{t-1}^{2}$ are previous periods' forecast variances, and $\epsilon_{t-i}^{2}$ are the news about volatility from previous periods, measured as the squared residuals from the mean specification.

\section{TGARCH}

$$
\sigma_{t}^{2}=\omega+\sum_{j=1}^{q} \beta_{j} \sigma_{t-j}^{2}+\sum_{i=1}^{p} \alpha_{i} \epsilon_{t-i}^{2}+\sum_{k=1}^{r} \gamma_{k} \epsilon_{t-k}^{2} I_{t-k}^{-}
$$

where $I_{t}^{-}=1$ if $\epsilon_{t}<0$ and zero otherwise. This means that bad news, i.e. $\epsilon_{t-i}<0$ are allowed to have a different impact compared to good news, or $\epsilon_{t-i}>0$. Asymmetric features in volatility exists if $\gamma_{i} \neq 0$.

\section{EGARCH}

$$
\log \left(\sigma_{t}^{2}\right)=\omega+\sum_{j=1}^{q} \beta_{j} \log \left(\sigma_{t-j}^{2}\right)+\sum_{i=1}^{p} \alpha_{i}\left|\frac{\epsilon_{t-i}}{\sigma_{t-i}}\right|+\sum_{k=1}^{r} \gamma_{k} \frac{\epsilon_{t-k}}{\sigma_{t-k}} .
$$

Again, asymmetric features in volatility exists if $\gamma_{i} \neq 0$. This specification allows for the leverage effect to be exponential, rather than quadratic as in the TGARCH specification above.

\footnotetext{
${ }^{2}$ I am grateful to Andrew Patton for generously providing a Matlab program for the
} estimation of unconditional and conditional copulas. 
To allow for thicker tails commonly observed in the distribution of financial time series, we use a Generalized Error Distribution (GED) instead of a normal distribution when modeling and estimating the marginal distributions. The GED was popularized in financial time series analysis by Nelson (1991). A random variable $x_{t}$ has a GED with zero mean, unit variance and tail parameter $\nu$ (where $\nu>0)$ if its probability density function can be written as:

$$
g\left(x_{t}\right)=\frac{\nu \exp \left[-(1 / 2)\left|x_{t} / \lambda\right|^{\nu}\right]}{\lambda 2^{(\nu+1) / \nu} \Gamma(1 / \nu)}
$$

where

$$
\lambda=\sqrt{\frac{2^{-2 / \nu} \Gamma(1 / \nu)}{\Gamma(3 / \nu)}} .
$$

When the GED parameter $\nu$ is equal to 2 , the probability density function reduces to that of the standard normal distribution. If $\nu<2$, the density has fatter tails than the normal density. Finally, if $\nu>2$, the density has thinner tails than the normal density. We thus expect to see values for the GED parameter to be lower than 2 for several of the markets.

To complete the specification of the marginal distributions, we also need to model the mean. Initial tests indicate that a few of the markets exhibit significant serial correlation in returns. To fully model the marginal distributions, we therefore adjust the mean specification to allow for autoregressive behavior when needed. When no serial correlation is found, only a constant is used when we estimate the mean equation. Having gone over the basic principles behind standard and conditional copulas as well as the estimation of the marginal distributions, we now turn to the empirical results.

\section{Empirical Results and Analysis}

Before analyzing the empirical results, we introduce the data used in this study. As a proxy for the Chinese stock market, we use the Shanghai Composite Index (SHCI). The SHCI is arguably the most commonly used index when studying China's equity markets. The S\&P 500 index and the Nikkei are used for the U.S. and Japan markets, respectively. Similarly, the Hang Seng Index is used as a proxy for the Hong Kong stock market. In order for us to be able to analyze China's financial market integration with Asia and Europe over time, the MSCI Asia (excluding Japan) and the MSCI Europe indices are used as proxies for the two regions. Finally, the MSCI World index is used as a proxy for the world market. All indices are gathered from Datastream and are of monthly frequency. The log returns in percentages are computed as $100 * \log \left(P_{t} / P_{t-1}\right)$, where $P_{t}$ is the price of the index at time $t$.

As discussed in the previous section, before the full dependence structure can be analyzed, we need to model the marginal distributions for each of the 
variables in the data sample. We test each of the three GARCH specifications discussed earlier in order to identify the most suitable model for each of the seven stock indices.

The results of the estimations of each of the different marginal distributions are presented in Table 1. To save space, we only include the estimation results for the optimal specification for each market. The AIC indicates that a standard $\operatorname{GARCH}(1,1)$ is preferable for all time series, except for Japan, for which an $\operatorname{EGARCH}(1,1)$ specification is used. Several of the series show signs of serial correlation. Suitable lagged values of the returns are therefore included in the mean equation for China, Asia, and Hong Kong. The LjungBox statistic indicates that the serial correlation in the standardized residuals from the estimations is insignificant in all of the seven cases. We can therefore conclude that we have dealt adequately with autocorrelation in the mean. Similarly, the Ljung-Box statistic for the variance equations shows that there are no signs of residual heteroscedasticity in any of the squared standardized residuals. The conditional variance thus seems to be correctly specified in all cases. The parameter for lagged volatility in the variance equation, $\beta$, indicates that volatility is very persistent in all seven cases, a common feature in international equity markets. In the case of Japan, the leverage parameter is very significant. However, the parameter is positive, indicating that positive news have a stronger effect than negative news. This result differs from the leverage effect, for which negative news have a stronger effect on subsequent volatility than positive news. The GED parameter is significant in all seven estimations. $\nu$ is lower than 2 in all cases except for Japan, indicating that most of the series have distributions with thicker tails compared to the standard normal distribution. To conclude, the mean and variance specifications seem to be correctly specified in all seven cases.

\section{[TABLE 1 HERE]}

Having estimated each of the marginal distributions, we then apply the probability integral transform to convert the standardized residuals of the marginal distributions into Unif $(0,1)$ distributions. To check that the specifications for the marginal distributions are correct, we also apply a test suggested by Diebold, Gunther, and Tay (1998). If the marginal distributions are specified correctly, the probability integral transform of the residuals will be i.i.d. Unif $(0,1)$. Diebold, Gunther, and Tay (1998) focus on the first four moments of the transformed series, or $\left(u_{t}-\bar{u}\right)^{k}$, where $u_{t}$ is the transformed series and $k=1,2,3,4$. We therefore create time series for the four moments for each of the seven transformed series and look at their autocorrelation functions. If the marginal distribution is incorrectly specified for the monthly returns series, then the autocorrelation function will reveal dependence in the different moments of the transformed time series. An overview of the autocorrelation function for each of the four transformed series and their four moments is presented in Table 2. The table shows the autocorrelation for 5, 10, 15, and 20 
lags, respectively. None of the probability integral transforms have any remaining dependence in the first four moments. The specified marginal distributions thus seem to capture the volatility dynamics of the processes as well as serial correlation in the mean. This means that we can use the transformed series when estimating the dependence structure between China and the other six markets.

\section{[TABLE 2 HERE]}

Knowing that we have modeled the marginal distributions correctly, we now turn to the estimation of the copulas. We start with unconditional copulas and look at the dependence structure between China's financial market and each of the six other markets. Table 3 shows the dependence parameter when applying the normal copula. The first row shows the level of dependence for the whole period. The next three rows present the dependence structure when we divide the sample into three subperiods of equal length. The dependence between China and each of the six markets is relatively modest for the whole sample period, an expected result if one considers how insulated the Chinese equity markets have been from the outside world. However, what is more interesting is the change over time in each of the six relationships. Looking at the dependence parameter and comparing between the different subperiods, it is clear that there is an increase in financial market integration between China and all six markets. The dependence is very low and even negative during the first subperiod, and then increases significantly during the two next subperiods. These results indicate that China's financial markets have gone from being very much insulated and unaffected by the outside world to becoming increasingly integrated with world markets over time.

\section{[TABLE 3 HERE]}

To better understand how dependence between the markets behave over time, the conditional copula approach is used on the six pairs of variables. Figure 1 shows the results when we apply a conditional normal copula to China and each of the six other markets. The time paths of the conditional dependence parameters support the initial results in Table 3. China's financial integration with the six markets is increasing over time. However, the movements vary significantly depending on market. There was a general decrease in the integration between China and Asia and between China and Hong Kong following the initial increase in market volatility during the Asian financial crisis in 1997-1998. The effect of the Asian financial crisis is much less pronounced in the dependence between China and Europe, China and Japan, China and the U.S., and China and the world. These results indicate that China was not as severely hit by the financial crisis as other countries in the region. Furthermore, the figure indicates that the current financial crisis that originated in the U.S. is causing a general increase in the dependence between China and other financial markets. The only market that China is not experiencing a significant increase in integration with during the last two years is that of Japan. 


\section{[FIGURE 1 HERE]}

Besides the apparent increases in dependence between China and different international financial markets, it is worth noting that the increase in financial integration seems to be especially strong between China and a few particular markets. The relationship between China and Hong Kong is getting stronger, an expected result that will be discussed in more detail in the following section. The dependence between China and Asia is also increasing significantly, indicating a strong trend in financial integration. Finally, and somewhat surprisingly, the conditional dependence between China and Europe seems to be increasing steadily over time, especially during the period 2002-2008. The financial market integration taking place between China and Japan seems more stable by comparison.

\section{Causes behind the Increasing Financial In- tegration}

The general view of China's financial markets is that they are almost completely insulated with a very limited relationship to international financial markets. To some extent, this view is correct. For instance, Johansson (2009b) shows that systematic risk in the two Chinese stock markets (Shanghai and Shenzhen) when measured against the world market is limited. The results indicate that there are a number of sharp and short-lived increases in systematic risk in these markets during the last decades and connect these changes to volatility increases due to shifts in government policy rather than a changing correlation pattern with the world market. However, as we have argued earlier in this paper, correlation is only one way of measuring dependence, and in some cases, there are alternatives that may be better suited to measure dependence between two financial markets.

The empirical results in the previous section highlight how the financial market integration between China and the rest of the world tends to increase over time during the 1990s and 2000s. Why do we come to this conclusion even though the markets have been so closed to the outside world? In this section we discuss a number of possible explanations, ranging from factors that can have had an impact early on to factors that tend to grow in importance as the Chinese economy as well as its financial markets mature. We begin with possible causes that are directly related to the financial markets, including different share classes, cross listings across national borders and a continued gradual financial liberalization. We then discuss more general economic causes, often a result of China's growing importance in the world economy. These factors include the world's increasing reliance on China as a manufacturing powerhouse, the internationalization of Chinese firms and how globalization results in similar effects on firm value regardless of where companies are listed 
or have their respective headquarters. ${ }^{3}$

\subsection{Share Classes}

As mentioned earlier, due to capital account restrictions in China, it is commonly argued that the domestic stock market is insulated from the rest of the world. There are, however, several reasons for why China's stock market can be expected to be affected by shocks in international markets. The first reason we discuss here concerns that of share classes. China's two stock exchanges in Shanghai and Shenzhen were established in 1990 and 1991, respectively. Beginning in 1992, the Chinese Securities and Regulatory Commission (CSRC) allowed domestic companies to issue what was called "Special Shares". The standard A-shares have been available to domestic investors, while foreign investors have invested in the Special Shares, later to be called B-shares. To facilitate trading in B-shares for foreign investors, these shares are denominated in U.S. dollars in Shanghai and in Hong Kong dollars in Shenzhen. Even though the different share classes have resulted in a seemingly segmented domestic stock market, it is natural to assume that there exists at least an indirect causal relationship between Chinese and foreign markets due to the possibility for international investors to trade in B-shares.

As an example, let us assume that there is a market-wide shock in China. This will affect both A- and B-shares simultaneously. The shock will then propagate into other markets through the effect it has on international investment portfolios when the value of B-shares changes. We can therefore assume that a domestic market-wide shock has indirect effects on international stock portfolios and thus indirect effects on other markets. As another example, assume that there is a sudden shock in international markets that affects B-shares in China. For instance, a shock in international markets may result in the repositioning in international investment portfolios, thus changing the overall demand for Chinese B-shares. Even though A- and B-shares are commonly seen as segmented markets, the Chinese government has imposed changes in the regulations that have weakened this segmentation. In 2001, it was decided that Chinese investors are allowed to invest in B-shares as well as A-shares. This change, put into effect on February 19, 2001, had a dramatic effect on the relationship between A- and B-shares. There was a sharp decline in the discount on B-shares as a result of the regulatory change, from an average of $75 \%$ down to $8 \%$ in just a few months (Karolyi and Li, 2003). Chan, Menkveld, and Yang (2007) analyze how information discovery is taking place in the Chinese stock market. Their findings indicate that before the regulatory change, the

\footnotetext{
${ }^{3}$ As Masson, Dobson, and Lafrance (2008) point out, the potential move away from a fixed exchange rate regime is most likely to increase future financial integration between China and the rest of the world significantly. The issue of China's exchange rate regime and its effect on the domestic economy has been discussed in numerous studies. We therefore do not analyze the potential effects on the country's future financial integration if a change in the exchange rate regime takes place further here.
} 
A-share market lead the B-share market in information discovery. After 2001, the causality was reversed. Wang and Di Iorio (2007) analyze the integration between A- and B-shares, Hong Kong, and the world market. Their results suggest that there is an increasing integration between A- and B-shares. It can therefore be assumed that changes originating in international markets can have an indirect effect on both A- and B-shares in China.

\subsection{Cross Listings}

Besides B-shares, foreign investors are able to invest in Chinese companies that are cross-listed, that is, they are listed in China as well as abroad. The perhaps strongest reason for why companies decide to list their shares in another country is that they seek to exploit the existence of a lower cost of capital. In a recent study on Chinese cross-listings, Zhang and King (2008) find that limitations of the domestic markets is a strong motivating factor for Chinese companies to list abroad. Their results also indicate that Chinese companies are motivated to raise capital in foreign equity markets since they provide a better access to capital markets and thus provide a lower cost of capital. Also, Zhang and King (2008) argue that the different legal and economic environments play a role in the decision to list abroad. ${ }^{4}$ There are a number of different venues for Chinese companies to list in, but the most common one is still that of Hong Kong. Shares of companies that are based in China and choose to list in Hong Kong are often called H-shares. There are also so-called red chips listed in Hong Kong. Red chips are shares of companies that have the major part of their business located in China but decide to list abroad for different reasons. Historically, cross-listed shares tend to be the largest and most successful mainland companies, with a higher level of transparency and better corporate governance than the average mainland company.

The fact that many of the companies that are listed abroad are also listed domestically combined with the fact that these companies tend to be the largest and most important ones in the Chinese economy makes it natural to assume that they create a direct relationship between the Chinese market and international markets. A recent study by Johansson and Ljungwall (2009) show that there are linkages between the markets in the so-called Greater China region. Cross-listings is most probably one of the reasons for the spillover effects found in that study. Wang and Di Iorio's (2007) analysis on market integration indicates that the A-share and Hong Kong markets are getting more integrated over time. The authors credit this development to the increased economic integration taking place between Hong Kong and the mainland. The significant number of cross-listings and the increasingly complex relationship between the markets in Hong Kong and the mainland constitute plausible reasons for the increasing relationship between China's equity markets and world markets.

\footnotetext{
${ }^{4}$ For a more detailed and thought-provoking analysis on why firms decide to list in other countries, see Karolyi (2006).
} 


\subsection{Financial Liberalization}

Since the beginning of the economic reforms in the end of the 1970s, financial reforms have taken place gradually. In response to the growing needs of well-functioning financial markets as the real economy grows, financial reforms have gained momentum during the last decade. Lee and Wong (2009) divides the financial reforms in China into two separate phases. The first phase, spanning from 1978 to 1997, involved the remaking of the domestic banking system, the establishment of the two stock exchanges, the development of the foreign exchange market, and the gradual development of the domestic bond market. During the second phase, from 1997 and forward, the focus has been on the deregulation of the domestic banking sector, general improvements of the financial markets, and increasing the integration with the global financial system.

During the second phase of financial reforms, the Chinese government has initiated policy changes that should have significant effects on the relationship between Chinese and global financial markets. Besides letting domestic investors trade in B-shares, the government now allows Chinese firms to open foreign exchange accounts. The implementation of first the Qualified Foreign Institutional Investor (QFII) program and later also the Qualified Domestic Institutional Investor (QDII) program is also more than likely to have a significant effect on the level of financial integration between China and the rest of the World. The QFII scheme was introduced in 2002 as a way to let a number of experienced foreign institutional investors get access to the Chinese domestic markets. The program sets a quota for how much the foreign institutions are allowed to invest, thus so far limiting the impact on the domestic market. Nevertheless, the movement towards more open domestic markets is clear. The QDII program was introduced in 2006 and originally covered only fixed-income products. However, the program was later expanded to cover equity products as well. There are macroeconomic structural reasons as well as effects for individual domestic investors that indicate the importance of the QDII program. The hot topic of China's external imbalances with the resulting influx of foreign liquidity and the pressure on the domestic currency to appreciate are obvious signs of the need for a more open capital account. Similarly, the possibility for domestic investors to invest in a much broader range of assets can have a very significant long-term wealth effect. As of 2006, regulations from the State Administration of Foreign Exchange (SAFE) state that Chinese individuals are allowed to exchange up to $\$ 20,0000$ or the equivalent of foreign currency every year.

It is clear that the second phase of financial liberalization in China will have effects on several levels. In terms of financial market integration, it can be assumed that the gradual opening of the Chinese capital account will result in an increase in the integration between the domestic financial markets and the world market. The empirical results in this study support this assumption, with evidence of continuous increases in financial market dependence between 
China and many of the major international markets since the mid-1990s.

\subsection{China's Increasing Trade and FDI Inflows}

During the last decades, China has gone from playing a marginal role in the world economy into becoming one of the most important global economic forces. A long period of unprecedented growth in foreign direct investment (FDI) has resulted in strong capital inflows as well as different spill-over effects to the Chinese economy. Another phenomenon in the Chinese economy, partly a result of the increasing FDI inflows and the presence of foreign companies in the country, is the very strong and persistent increase in exports. The combination of the increases in FDI inflows and exports means that the domestic economy is becoming more and more intertwined with the world economy, or at least with the economies with which China is engaged in significant trade and the economies from which China is receiving the major parts of its FDI inflows.

China's trade with the rest of the world has not only increased dramatically, with an export growth of over 500\% since 1992 (Amiti and Freund, 2008). The trading partners and the composition of the trade is also of considerable interest. China's economic development is often compared to that of India. In terms of trade, the two large economies are very different, however, as pointed out in several studies (e.g. Bussière and Mehl, 2008). For instance, while China's share in total global trade has increased to $7 \%$ in 2006, India's share has remained at a modest 1\%. Another and perhaps more important difference is the trade linkages that have developed between these two countries and the rest of the world. Bussière and Mehl (2008) show that China is responsible for a significant share of total foreign trade in goods in the U.S., the U.K, Japan, and the euro area. Similarly, China's general trade intensity is higher as are its bilateral trade linkages. Bussière and Mehl (2008) argue that this is largely because China today constitutes an integral part of the "Asian production chain", a commonly used term for the well-developed regional production network. A clear sign of this is that a large part of China's total imports come from neighboring countries in the region, while no such pattern can be found for India. Overall, China's trade links are one of the main causes for the country's phenomenal growth during the last decades.

The increase in economic ties between China and the rest of the world is likely to result in increased financial integration with global markets. As a very large number of domestic firms are dependent on contracts with multinational firms, adverse shocks to the demand for foreign firms' goods abroad can have an indirect but equally significant impact on a number of domestic firms. For instance, if a company that is listed on a foreign stock exchange suddenly is affected by negative sentiments in global consumer markets, a company listed on one of the Chinese stock exchanges that produce and sell products to the foreign company is negatively affected as well. In this very simple example, a 
negative impact on the market value of the foreign firm would be followed by a similar loss in market value of the Chinese firm. It is natural to assume that the development of the Chinese economy into the world's manufacturing center results in an indirect increase in financial market integration, even though the causal effect is difficult to measure in absolute terms.

\subsection{The Internationalization of Chinese Firms}

The topic of the current and future internationalization of Chinese firms is indeed both sensitive and intriguing. China's first sovereign wealth fund handled by China Investment Corporation and several other state-owned entities responsible for investing abroad have made many international observers uneasy. However, China's outward foreign direct investment (OFDI) is still modest in size. Also, a majority of the investments overseas have focused on mining and manufacturing, with a $65 \%$ and $25 \%$ share of total OFDI, respectively (Schüler-Zhou and Schüller, 2009). Schüler-Zhou and Schüller argue that the current patterns of China's OFDI indicate that investment choices are heavily influenced by the government. Leaving the political dimensions out of the analysis, the focus of the following discussion is on the effects that Chinese firms' interest abroad may have on financial integration.

Even though the size of OFDI from China up to now is relatively modest, the trend is clear. The Chinese government has formulated a policy that spells out the desire to create a number of national corporate champions that will be able to compete globally. One of the first examples of the expansion of Chinese firms abroad is Lenovo, the computer manufacturer that acquired IBM's laptop division in 2004. Besides straightforward acquisitions of brand names such as in the case of Lenovo and IBM, several of China's largest companies are increasingly turning outwards in their pursuit to expand their operations. For instance, Boisot and Meyer (2009) point out that one reason for why an increasing number of Chinese companies that are relatively small by international standards choose to internationalize early in their development is that these companies face increasing costs due to protectionism and inefficient domestic logistics. A natural next step is therefore to internationalize their operations in the pursuit of more efficient institutions. Examples of large Chinese companies that have already internationalized their operations include the white-goods manufacturer Haier, the telecom solutions provider Huawei, and the steel company Baosteel.

As Chinese companies expand across national borders and regions, they start to compete with multinational companies from other countries. Even though this holds true for the domestic arena in China, limited access to the Chinese market in many industries as well as the limited purchasing power in the country up to recently have to some extent inhibited such competition inside China. The current internationalization of Chinese firms thus marks a new turning point for the country's integration with the world economy. 
As Chinese companies begin to compete in international markets, they are more likely to be affected by similar shocks as their international competitors. Take the telecom solutions industry as an example. As Huawei is becoming a serious contender to multinational companies like Ericsson and Nokia, these companies are bound to be affected by changes in the global demand for their products and services. This means that a severe adverse demand shock in a large market can be expected to result in a decrease in firm value not only for the competing international companies but also for the Chinese counterpart. This development should hold true for a number of sectors in which Chinese companies has put extra energy into trying to build up an international presence. For instance, China was a net importer of steel for a long period of time. Recently, this has changed, as large Chinese steel companies are competing globally with other multinational steel companies. This development indicates that Chinese companies and other multinational companies will be affected similarly by changes in market demand. This is perhaps particularly true when it comes to the raw material sector, an industry where Chinese companies are currently expanding aggressively around the world. Overall, the internationalization of Chinese firms is most likely to result in stronger comovements between them and international firms, thereby strengthening the relationship between the domestic and international financial markets.

\section{Conclusion}

Studies on financial integration show that a country's financial markets tend to become more integrated with international markets as financial liberalization is initiated. Financial integration has important implications not only for domestic and foreign investors, but also for policy makers who need to understand the factors that influence movements in financial markets. In this study, we focus on China's financial market integration with a number of important international markets. We limit the analysis to equity markets, partly because the access to reliable data, and partly because the Chinese equity market has received significant attention both domestically and abroad. We propose the use of copulas when measuring financial integration, since it has been shown that copulas are able to capture dependence that is not identified by regular linear correlation measures. We therefore first model and estimate the marginal distributions for each of the seven equity markets using conditional volatility models. We then use the residuals from the marginal estimation to obtain the copulas. Using both unconditional and conditional copulas, we are able to show that China's financial market is becoming increasingly integrated with a number of the major international markets included in the study. Furthermore, the trend of increasing financial integration has continued during the current financial crisis that originated in the U.S. The support for increased financial integration begs the question why such a development is taking place.

We provide a number of plausible explanations for why China is becoming 
more financially integrated with the world. Beginning with structural features in the financial markets, we argue that the changing nature of the before so segmented share classes is resulting in closer ties between A-, B-, H-shares and thereby with shares in other markets. Another possible reason for the increasing financial integration is that more and more Chinese companies are listed both in domestic markets and abroad. One result of this phenomenon may well be an increasing integration with international markets, since international investors get access to Chinese companies. Sceptics may argue that these markets are perfectly segmented. However, we believe that investor sentiments influence movements in these markets similarly. For instance, if there are prolonged negative sentiments in the mainland markets, this is most likely to cause a similar drop in cross-listed shares, thus influencing both domestic and international investment portfolios. Furthermore, the implementation of the QFII and QDII programs brings with it new channels for integration in the sense that both domestic and international investors are getting access to the same markets. It can be expected that these gradual steps of financial liberalization have caused and will continue to cause significant increases in China's financial integration with the rest of the world. Besides the issues related to the structure of the financial markets and the financial reforms, we also discuss additional plausible reasons for why China's markets is becoming more integrated with the international markets. Trade and FDI are two such reasons, constituting channels for increasing economic ties across national borders and thus an increasing sensitivity for shocks in different markets. Similarly, we argue that the ongoing internationalization of Chinese firms, albeit at a modest level so far, may constitute a significant factor behind the current, and not the least future level of financial integration.

To conclude, the empirical results in this study indicate that financial integration is increasing between China and several major international markets. Furthermore, a number of possible reasons for the increase in financial integration discussed in this paper indicate that financial integration between China and the rest of the world is likely to continue to increase as long as the Chinese government continues its gradual reforms. Increasing financial integration has strong implications for both investors and policy makers. As domestic investors are getting access to international financial markets, they need to understand how these markets relate to the domestic markets in order to construct optimal portfolios. Similarly, foreign investors need to understand how Chinese markets are affected by shocks in other markets, and whether the importance of these effects will increase. For policy makers, it is important to understand how the data-generating process in the domestic financial markets is changing. When the two stock exchanges in Shanghai and Shenzhen were established in the early 1990s, they were in many ways truly insulated from international markets. Policy makers in China were thus able to focus on domestic matters and domestic causes of market instability. As financial integration between China and the rest of the world increases, however, these policy makers are 
facing an increasingly complex situation in which not only domestic shocks affect the market. Now, they also need to understand how shocks and negative sentiment in markets such as the U.S., Europe, and the rest of Asia propagate to the Chinese stock market. 


\section{References}

[1] Agénor, P.-R., 2003. Benefits and Costs of International Financial Integration: Theory and Facts, World Economy, 26, 1089-1118.

[2] Amiti, M. \& Freund, C., 2008. The Anatomy of China's Export Growth, World Bank Policy Research Working Paper, No. 4628.

[3] Bailey, W. \& Jagtiani, J., 1994. Foreign Ownership Restrictions and Premiums for Intemational Investment: Some Evidence from the Thai Capital Market, Journal of Financial Economics, 36, 57-88.

[4] Bekaert, G., 1995. Market Integration and Investment Barriers in Emerging Equity Markets, World Bank Economic Review, 9, 75-107.

[5] Bekaert, G. \& Harvey, C.R., 1995. Time-Varying World Market Integration, Journal of Finance, 50, 403-44.

[6] Bekaert, G., Harvey, C.R. \& Lumsdaine, R.L., 2002. The Dynamics of Emerging Market Equity Flows, Journal of International Money and Finance, 21, 295-350.

[7] Boisot, M. \& Meyer, M.W., 2008. Which Way through the Open Door? Reflections on the Internationalization of Chinese Firms, Management and Organization Review, 4, 349-65.

[8] Bollerslev, T., 1986. Generalized Autoregressive Conditional Heteroskedasticity, Journal of Econometrics, 31, 307-27.

[9] Bussière, M. \& Mehl, A., 2008. China's and India's Roles in Global Trade and Finance: Twin Titans for the New Millenium?, European Central Bank Occasional Paper Series, No. 80.

[10] Carrieri, F., Errunza, V. \& Hogan, K. 2007. Characterizing World Market Integration through Time, Journal of Financial and Quantitative Analysis, 42, 915-940.

[11] Chan, K., Menkveld, A.J. \& Yang, Z. 2007. The Informativeness of Domestic and Foreign Investors' Stock Trades: Evidence from the Perfectly Segmented Chinese Market, Journal of Financial Markets, 10, 391-415.

[12] Cheung, Y.-W., Chinn, M.D. \& Fujii, E., 2003. China, Hong Kong, and Taiwan: A Quantitative Assessment of Real and Financial Integration, China Economic Review, 14, 281-303.

[13] Cheung, Y.-W., Chinn, M.D. \& Fujii, E., 2005. Dimensions of Financial Integration in Greater China: Money Markets, Banks, and Policy Effects, International Journal of Finance and Economics, 10, 117-32. 
[14] Diebold, F.X., Gunther, T.A. \& Tay, A.S., 1998. Evaluating Density Forecasts with Applications to Financial Risk Management, International Economic Review, 39, 863-83.

[15] Sellin, P. \& Werner, I., 1993. International Barriers in General Equilibrium, Journal of International Economics, 34, 2107-138.

[16] Eichengreen, B. \& Park, Y.C., 2005. Financial Liberalization and Capital Market Integration in East Asia, In Park, Y.C., Ito, T., \& Wang, Y. (Eds.), A New Financial Market Structure for East Asia, Cheltenham: Edward Elgar.

[17] Eun, C.S. \& Janakiramanan, S., 1986. A Model of International Asset Pricing with a Constraint on the Foreign Equity Ownership, Journal of Finance, 41, 897-914.

[18] Fisher, R.A., 1932. Statistical Methods for Research Workers, Edinburgh: Oliver and Boyd.

[19] Glosten, L.R., Jaganathan, R. \& Runkle, D., 1993. On the Relation between the Expected Value and the Volatility of the Normal Excess Return on Stocks, Journal of Finance, 48, 1779-1801.

[20] Harvey, C., 1991. The World Price of Covariance Risk, Journal of Finance, 46, 111-57.

[21] Joen, J., Oh, Y. \& Yang, Y., 2005. Financial Market Integration in East Asia: Regional or Global?, Korea Institute for International Economic Policy.

[22] Johansson, A.C., 2009. An Analysis of Dynamic Risk in Greater China's Equity Markets, Journal of Chinese Economic and Business Studies, forthcoming.

[23] Johansson, A.C. \& Ljungwall, C., 2009. Spillover Effects among the Greater China Stock Markets, World Development, 37, 839-51

[24] Jorion, P. \& Schwartz, E., 1986. Integration Versus Segmentation in the Canadian Stock Market, Journal of Finance, 41, 603-13.

[25] Karolyi, G.A., 2006. The World of Cross-Listings and Cross-Listings of the World: Challenging Conventional Wisdom, Review of Finance, 10, 99-152.

[26] Karolyi, G.A. \& Li, L., 2003. A Resolution of the Chinese Discount Puzzle, Unpublished Manuscript.

[27] Lee, J. \& Wong, A., 2009. Impact of Financial Liberalization on Stock Market Liquidity: Experience of China, Hong Kong Monetary Authority Working Paper 03/2009. 
[28] Masson, P., Dobson, W. \& Lafrance, R., 2008. China's Integration into the Global Financial System, Bank of Canada Review, Summer 2008, 17-29.

[29] Moshirian, F., 2008. Globalisation, Growth, and Institutions, Journal of Banking and Finance, 32, 472-79.

[30] Moshirian, F., 2009. Can an Asia Pacific Community, Similar to the European Community, Emerge?, Journal of Banking and Finance, 33, 2-8.

[31] Nelson, D., 1991. Conditional Heteroskedasticity in Asset Returns: A New Approach, Econometrica, 59, 347-70.

[32] Obstfeld, M., 1994. Risk Taking, Global Diversification, and Growth, American Economic Review, 84, 1310-29.

[33] Patton, A., 2006. Modeling Asymmetric Exchange Rate Dependence, International Economic Review, 47, 527-56.

[34] Rodriguez, J.C., 2007. Measuring Financial Contagion: A Copula Approach, Journal of Empirical Finance, 14, 401-23.

[35] Rosenblatt, M., 1952. Remarks on Multivariate Transformation, The Annals of Mathematical Statistics, 23, 470-72.

[36] Shin, K. \& Sohn, C.-H., 2006. Trade and Financial Integration in East Asia: Effects on Co-Movements, World Economy, 29, 1649-69.

[37] Schüler-Zhou, Y. \& Schüller, M., 2009. The Internationalization of Chinese Companies: What Do Official Statistics Tell Us about the Chinese Outward Foreign Direct Investment?, Chinese Management Studies, forthcoming.

[38] Sklar, A., 1959. Fonctions de répartition à $n$ dimensions et leurs marges, Publications de l'Institut Statistique de l'Université de Paris, 8, 229-31.

[39] Solnik, B., 1974. The International Pricing of Risk: An Empirical Investigation of the World Capital Market Structure, Journal of Finance, 29, 48-54.

[40] Stehle, R., 1977. An Empirical Test of the Alternative Hypothesis of National and International Pricing of Risky Assets, Journal of Finance, 32, 493-502.

[41] Stulz, R.M., 1981. On the Effects of Barriers to International Investment, Journal of Finance, 36, 923-34.

[42] Stulz, R.M. \& Wasserfallen, W., 1995. Foreign Equity Investment Restrictions, Capital Flight, and Shareholder Wealth Maximization, Review of Financial Studies, 8, 1019-58. 
[43] Wang, Y. \& Di Iorio, A., 2007. Are the China-Related Stock Markets Segmented with both World and Regional Stock Markets?, Journal of International Financial Markets, Institutions and Money, 17, 277-90.

[44] Zhang, C. \& King, T.-H.D., 2008. The Decision to Cross-List: The Case of Chinese IPOs and ADRs, Unpublished Manuscript. 


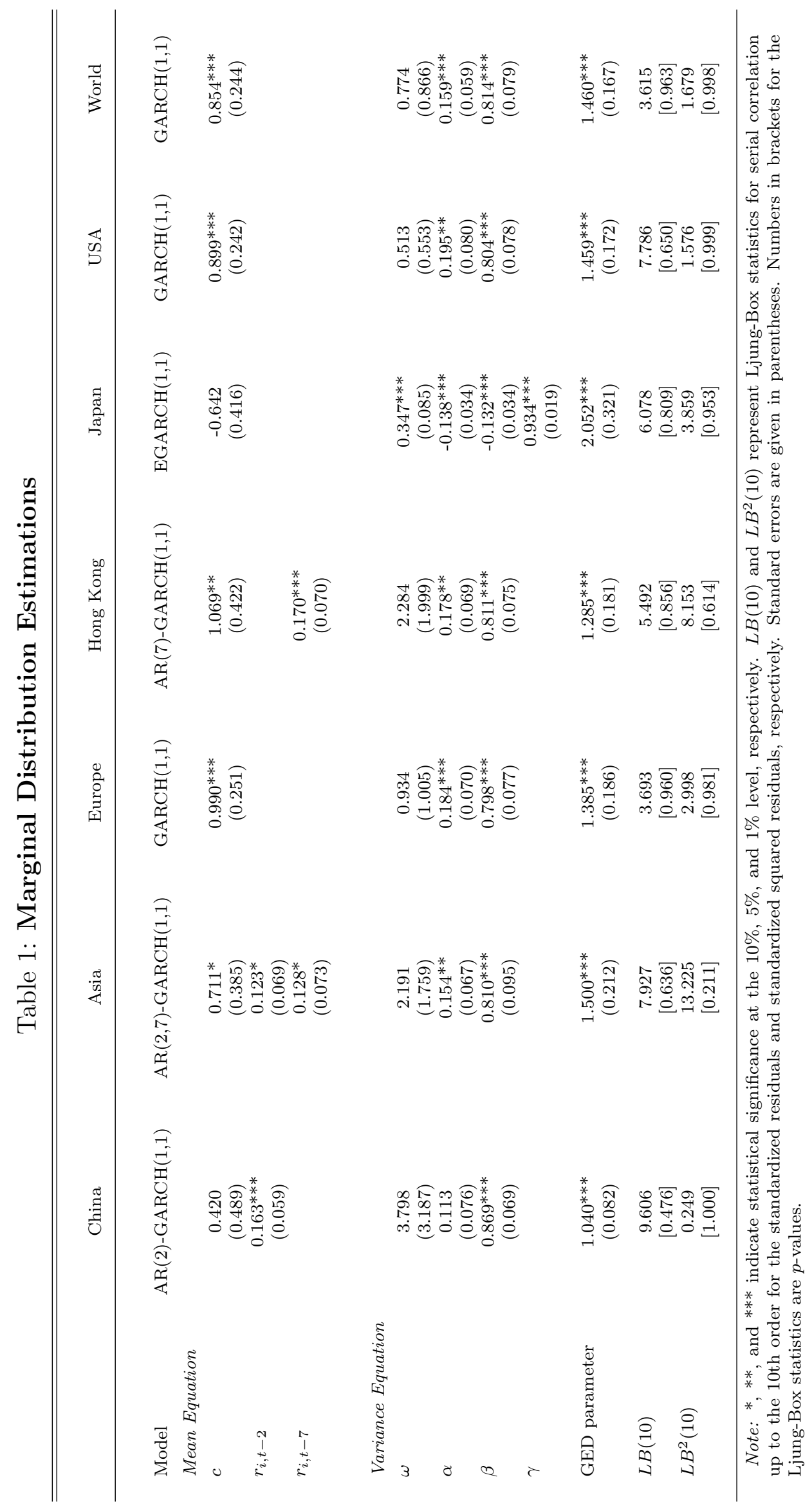




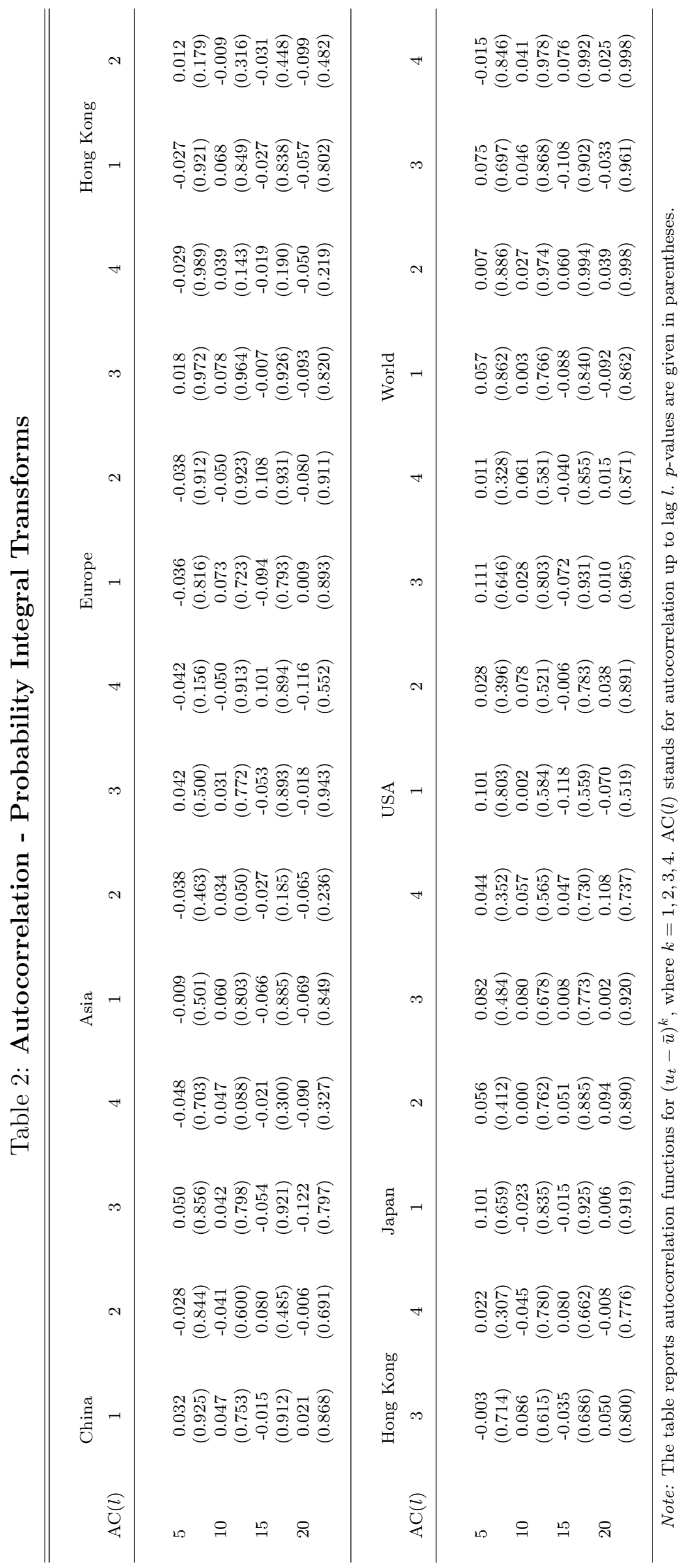


Table 3: Unconditional Dependence with China

\begin{tabular}{lcccccc}
\hline \hline & & & & & & \\
& Asia & Europe & Hong Kong & Japan & USA & World \\
& & & & & & \\
& & & & & & \\
& & & & & & \\
Whole Period & 0.173 & 0.145 & 0.157 & -127 & 0.139 & 0.148 \\
Period 1 & -0.111 & -0.210 & -0.155 & -0.112 & -0.139 & -0.181 \\
Period 2 & 0.072 & 0.030 & 0.133 & 0.214 & 0.086 & 0.068 \\
Period 3 & 0.513 & 0.513 & 0.479 & 0.286 & 0.428 & 0.485 \\
\hline
\end{tabular}



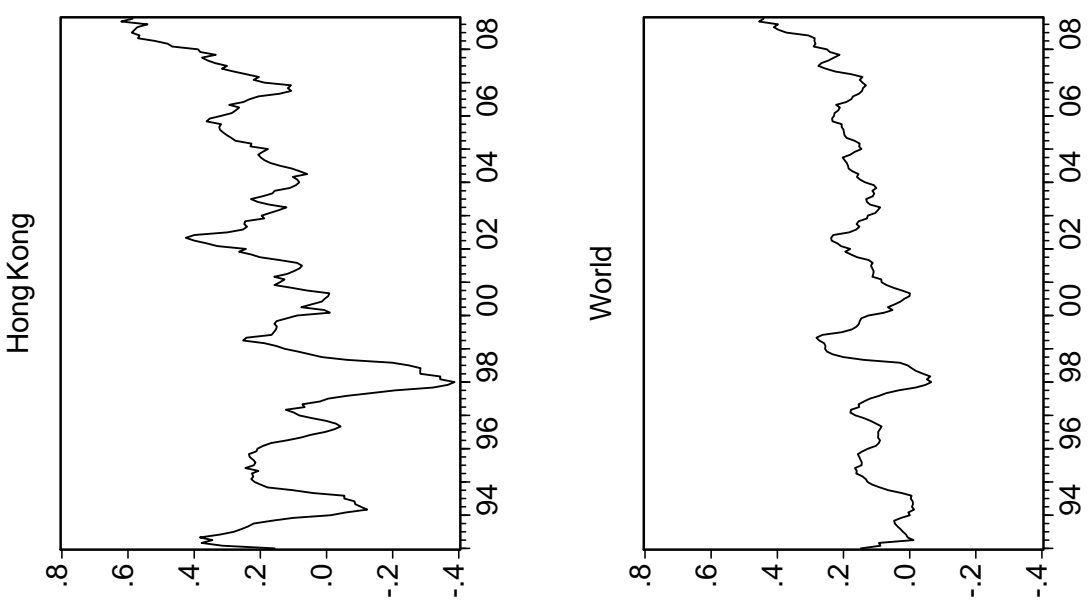

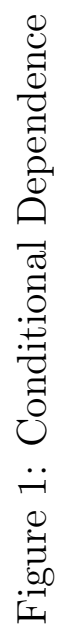
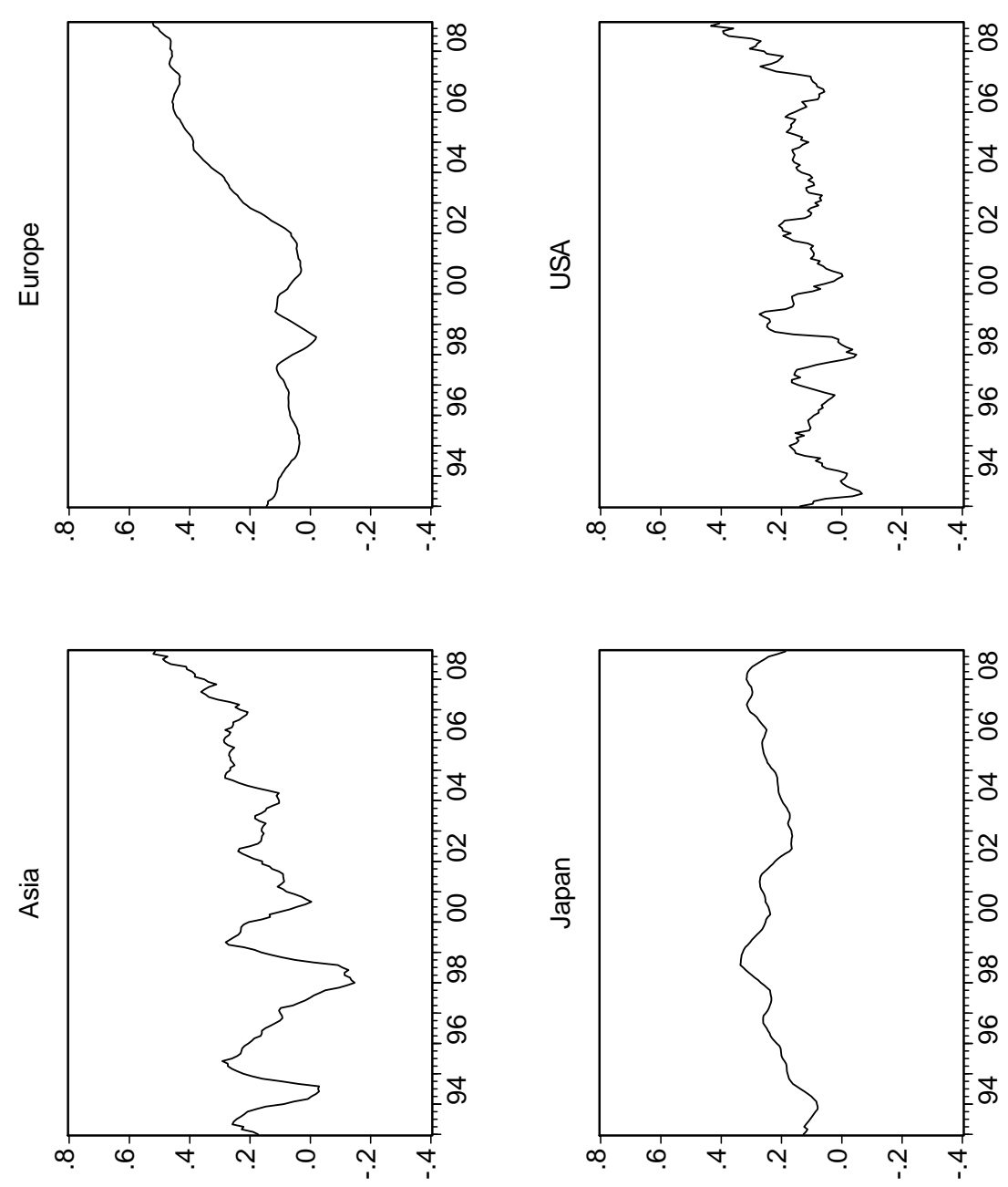